\title{
LA GESTIÓN TEMÁTICA COMO MARCADOR DE DÉFICIT LINGÜIISTICO PRIMARIO EN PERSONAS CON DIAGNÓSTICO DE PRIMER EPISODIO DE ESQUIZOFRENIA: UN ESTUDIO EN UNA MUESTRA CHILENA*
}

\author{
THE THEMATIC MANAGEMENT LIKE A SCOREBOARD \\ OF PRIMARY DEFICITS OF LANGUAGE IN THE PEOPLE \\ DIAGNOSED WITH THE FIRST SCHIZOPHRENIA OF EPISODE: A \\ STUDY IN A CHILEAN SAMPLE
}

\author{
ALICIA FIGUEROA \\ Universidad de Chile \\ aliciafigueroa@med.uchile.cl \\ EDUARDO DURÁN \\ Universidad de Chile \\ eduran2009@gmail.com \\ SONIA OYARZÚN \\ Universidad de Chile \\ soniarzun@gmail.com
}

\section{RESUMEN}

En esta investigación se analiza la gestión temática en una muestra de 50 entrevistas clínicas realizadas a personas con diagnóstico de esquizofrenia crónica y de primer episodio, desde la perspectiva de la lingüística clínica aplicada a la psiquiatría. Específicamente se propone determinar si existen diferencias en la gestión temática entre ambos grupos de pacientes. Asimismo, a fin de probar si constituye un marcador de déficit primario, se pretende verificar la relación entre la gestión temática, el estadio de la enfermedad y el sexo. El análisis de los datos, en primer lugar demuestra que es posible observar la pérdida

* Este trabajo se enmarca en el proyecto de investigación interdisciplinario: LEPSI (LEnguaje, PSicosis e Intersubjetividad. Un estudio en población chilena) orientado a la pesquisa de marcadores psicolingüísticos de psicosis de primer episodio. Proyecto de la Unidad de Psicolingüística Clínica, Departamento de Psiquiatría y Salud Mental, Campus Sur, Facultad de Medicina de la Universidad de Chile y que se está ejecutando en el Complejo Asistencial Barros Luco, CABL para el período 2016-2020 bajo la supervisión del Servicio de Salud Metropolitano Sur, SSMS. 
de la unidad temática, la presentación frecuente de tópicos sin desarrollo referencial y saltos topicales en personas con esquizofrenia de primer episodio. En segunda instancia, las variables estadio de la enfermedad y sexo presentan significación estadística, por lo cual, es posible considerar la gestión temática como un marcador primario de déficit pragmalingüístico para esquizofrenia.

Palabras clave: Gestión temática, esquizofrenia, primer episodio, marcador primario.

\section{ABSTRACT}

In this research the issue management is analyzed in a sample of 50 clinical interviews with people diagnosed with chronic schizophrenia and first episode, from the perspective of linguistics applied to clinical psychiatry. Specifically it proposes to determine if differences exist in the thematic management between both groups of patients. Likewise, in order to try if it constitutes a scoreboard of primary deficit one tries to check the relation between the thematic management, the stadium of the disease and the sex. Also, in order to test whether it is a marker of primary deficit is to verify the relationship between the subject management, disease stage and sex. The analysis of the information, first it demonstrates that it is possible to observe the loss of the thematic unit, the frequent presentation of topics without referential development and of leaps of discursive topics in persons with schizophrenia of the first episode. Secondly, the variables disease stage and sex have statistical significance, therefore, it is possible to consider the issue management as a primary marker of pragmalinguistic deficit schizophrenia.

Keywords: Thematic management, schizophrenia, the first episode, primary scoreboard.

Recibido: 30.08.2016. Aceptado: 19.05.2017.

\section{INTRODUCCIÓN}

- $\mathrm{n}$ los últimos años la interfaz entre lingüística clínica y psiquiatría ha conEseguido progresos significativos en la comprensión de aspectos centrales de patologías como la esquizofrenia y su impacto en las vidas de quienes la padecen (Morice e Ingram, 1983; Laguna y Turull, 2000; De Lisi, 2001; Salavera y Puyuelo, 2010). La incorporación de métodos y modelos tomados de la lingüística ha hecho posible realizar precisiones conceptuales específicas sobre los fenómenos comunicativos estudiados, puesto que en psiquiatría la comprensión de la conducta humana requiere una mirada holística (Morice e Ingram, 1983; Laguna y Turull, 2000; De Lisi, 2001; Salavera y Puyuelo, 2010). En el presente trabajo se propone describir las características de algunos indicadores lingüísticos que presentan disfunción en el discurso de personas con diagnóstico de esquizofrenia 
crónica y de primer episodio (Figueroa, 2015). Se analizará la gestión temática, específicamente, la unidad temática y los tópicos discursivos en el marco de la entrevista clínica, que constituye el instrumento más relevante para la indagación psiquiátrica. Nuestro objetivo general es determinar si existen diferencias en la gestión temática entre ambos grupos de pacientes. A su vez, el objetivo específico de este trabajo es establecer la posible relación entre el estadio de la enfermedad, el sexo y los fenómenos discursivos estudiados. La hipótesis del estudio es que la gestión temática constituye un marcador precoz de alta sensibilidad por presentarse en el primer episodio. Para tales propósitos se analizaron 50 entrevistas de sujetos con diagnóstico de esquizofrenia crónica y de primer episodio, constituyendo una muestra representativa de la patología.

\section{MARCO CONCEPTUAL}

\subsection{La esquizofrenia}

A causa de la ausencia de marcadores biológicos, el diagnóstico de la esquizofrenia se basa, fundamentalmente, en la historia del desarrollo de los síntomas, la entrevista clínica y la observación de las conductas de la persona afectada. Se utiliza como marco de referencia los criterios del DSM y el CIE-10, en los que se configura un conglomerado de síntomas que se presentan por un período de tiempo y que generan un deterioro de las condiciones vitales de adaptación al entorno. $\mathrm{Su}$ alta morbimortalidad, multidimensionalidad etiológica y curso deteriorante la transforman en un desafío constante para la salud pública y en un permanente reto para la psiquiatría (Crow, 1997; Castilla del Pino, 1991; Andreasen y Grove, 1995; MacKenna y Oh, 2005). Al situarse en etapas precoces del ciclo vital, se asocia no sólo a un deterioro neurocognitivo y psicosocial significativo, sino que, además, de no contar con un tratamiento oportuno y eficaz tenderá a la cronicidad. Representa un alto costo para el sistema de salud, el sujeto, su familia y sus cuidadores, y no existe hasta ahora un tratamiento que logre la remisión de la enfermedad; asimismo, sus manifestaciones siempre "implican una serie de disfunciones cognitivas, conductuales y emocionales, no hay un solo síntoma que sea patognomónico de la enfermedad" (DSM-V, 2014, p. 100).

Al mismo tiempo, a pesar de que la impronta evolutiva depende en forma aleatoria de la adherencia a los tratamientos psicofarmacológicos, terapéuticos y a los componentes genéticos predisponentes, el factor más significativo en la evolución de la enfermedad es la precocidad del diagnóstico. Una mayor duración de la psicosis no tratada (DUP) ${ }^{1}$ se relacionaría con un inicio insidioso de la enfermedad,

${ }^{1}$ DUP: Duration of Untreatment Psicosis (McGorry, Yung y Phillips, 2003). 
una propensión a rehospitalizaciones y una menor respuesta a los fármacos. Por otro lado, la reducción del período entre el inicio de los síntomas psicóticos y el comienzo del tratamiento, evitaría mayores daños neurocognitivos, favoreciendo una evolución más benigna (McGorry, et al., 2003). Otros factores que influyen en la evolución del cuadro son el sexo y la edad de inicio de la enfermedad. En forma reciente se ha descubierto que ambos factores incidirían en las características clínicas de pacientes del espectro esquizofrénico, demostrándose que los hombres tienen un inicio más temprano y un curso de la enfermedad con mayor deterioro (Usall, 2003; Sánchez, Téllez y Jaramillo, 2012). Como ya se señaló, para llegar a una comprensión integrada de esta afección es imprescindible que se complementen disciplinas diferentes con la capacidad de generar una interfaz explicativa para profundizar en su conocimiento. Se considera fundamental el hecho de que una de las áreas más afectadas es la relacionada con el ámbito de lo social y, por ende, de las competencias intersubjetivas. Las capacidades funcionales como la comunicación y la interacción son actividades sociales que adquieren ribetes casi inabordables para quienes sufren de patologías psiquiátricas.

\title{
2.2. El lenguaje en la esquizofrenia
}

En las personas con esquizofrenia las interacciones comunicativas evidencian aspectos deficitarios en el nivel semántico y pragmático (Leroy y Beaune, 2008; Ditman y Kuperberg, 2010; Salavera y Puyuelo, 2010, Figueroa, 2015). Existe una serie de disfunciones comunicativas visibles desde el primer episodio que darían cuenta de un déficit temprano de funciones asociadas a la Teoría de la Mente (Premack y Woodruff, 1978), área de la cognición que ha sido descrita como:

\begin{abstract}
"[...] la habilidad para comprender y predecir la conducta de otras personas, sus conocimientos, sus intenciones y sus creencias. Desde este punto de vista, este concepto se refiere a una habilidad 'heterometacognitiva', ya que hacemos referencia a cómo un sistema cognitivo logra conocer los contenidos de otro sistema cognitivo diferente de aquel con el que se lleva a cabo dicho conocimiento" (Tirapu-Ustárroz, Pérez-Sayes, Erekatxo-Bilbao, Pelegrín-Valero, 2007, p. 479).
\end{abstract}

Considerando que la Teoría de la Mente resulta de vital interés como base para el tratamiento de personas con psicosis, el estudio del desempeño comunicativo como rasgo inherente de las capacidades inferenciales se configura como una vía de acceso al funcionamiento cognitivo general. En este contexto, se sostiene que es posible distinguir dos niveles diferenciadores de fenómenos discursivos en personas con esquizofrenia (Figueroa, 2017). Un nivel primario, que corresponde a un conjunto de indicadores presentes desde el primer episodio y que es susceptible 
de ser considerado como marcador de déficit temprano por afectar no sólo el diagnóstico, sino también el pronóstico de la enfermedad. Asimismo, hay indicadores que se consideran secundarios por corresponder a un deterioro en el funcionamiento comunicativo de mayor consideración y por presentarse invariablemente en personas que se encuentran en la etapa de cronicidad. A juicio de los autores del presente trabajo, existiría una relación intrínseca entre la cantidad de episodios psicóticos, el déficit en funcionalidad social y la aparición de estos rasgos secundarios en el discurso (Figueroa, 2015).

Para la tarea a realizar, se adoptará el enfoque de la lingüística clínica funcional, porque facilita la tarea de reunir evidencia del perfil comunicativo de patologías mentales o neurológicas graves dentro de los parámetros del trabajo clínico con pacientes psiquiátricos (Gallardo Paúls y Hernández Sacristán, 2013). Como es sabido, la lingüística clínica no es un paradigma teórico, por el contrario se la describe como "[...] la aplicación de la lingüística al campo de las patologías del lenguaje, y su manifestación profesional más directa es, obviamente, la logopedia, terapia del lenguaje o fonoaudiología” (Gallardo Paúls y Valles, 2008, p. 34). La interacción médico-paciente representa un imbricado procesamiento comunicativo además de ser un marco ideal para las pesquisas de algunas dificultades funcionales, a la par de la identificación de posibles alteraciones de la cognición presentes en la esquizofrenia y en otras enfermedades mentales (Kuperberg, 2000; Fernández, 2015). Su multidimensionalidad presenta una gran ventaja informativa y, en este sentido, son conocidos los aportes de Labov y Fanshel (1977), quienes propusieron un "análisis exhaustivo del discurso", que es un método basado en el examen acucioso de un tramo de quince minutos de la entrevista clínica desde un enfoque que toma elementos de diferentes campos teóricos, como por ejemplo, el análisis del discurso, el análisis de la conversación, la pragmática y la sociolingüística interaccional, para aplicarlos en forma complementaria. Además, estos autores establecieron el análisis del contexto comunicativo global como condición indispensable para alcanzar una interpretación adecuada de las manifestaciones discursivas de los pacientes.

En el marco de la interacción médico-paciente se ha avanzado en la descripción del comportamiento comunicativo de personas con esquizofrenia crónica, como lo testimonian múltiples estudios (Chaika y Lambe, 1985; Piro, 1987; Chapman y Chapman, 1987; Laguna y Turull, 2000; Belinchón, 1991; Vargas, 2003; Salavera y Puyuelo, 2010). Sin embargo, a pesar de disponer de técnicas experimentales cada vez más sofisticadas, todavía no se incluyen aspectos básicos de suma relevancia, como por ejemplo, los perfiles lingüísticos de las psicosis de primer episodio. Las razones que impiden este acercamiento apuntan no sólo a la dificultad para reclutar personas diagnosticadas, sino también a la tendencia de muchos investigadores a emplear de forma preferente o exclusiva métodos experimentales, como la aplicación de instrumentos estandarizados, mediciones neurobiológicas 
o el análisis de muestras de habla procesadas con herramientas informáticas, excluyendo así del análisis los aspectos intersubjetivos que sólo son visibles en la interacción, el recurso medular de la psiquiatría. Es fundamental recordar que es mediante el trabajo clínico donde se dirime la condición del paciente; por tanto, en la medida que centremos los análisis en este ámbito, se facilitará una visión más integrada en la proyección de herramientas de evaluación diagnóstica y la consecuente generación de nuevos dispositivos de rehabilitación. La lingüística clínica funcional se ajusta a estas necesidades, pues es un enfoque aplicado que aborda tanto la comprensión y el estudio de aquellos aspectos disfuncionales del lenguaje, como la evaluación de los recursos y las herramientas de que dispone aún el paciente (Gallardo Paúls y Valles, 2008). Tomando en cuenta estos objetivos centrales de la disciplina será más pertinente y estratégico realizar un estudio que abarque aspectos generales del lenguaje y que los integre a la evaluación del desempeño comunicativo, en amplio sentido.

\subsection{La gestión temática en el discurso de personas con esquizofrenia}

El concepto de gestión temática que se enmarca en el trabajo de Tomlin, Forrest, $\mathrm{Pu}$ y Kim (1997), concierne a la tarea intersubjetiva en la que los hablantes procesan la información en tiempo real en una situación comunicativa específica. La gestión temática sería una de las cuatro dimensiones de procesamiento de la información denominadas por el autor gestión de la información. Tomlin et al. (1997) sostienen que en la producción del discurso los hablantes deben enfrentarse, por un lado al problema de la integración del conocimiento, es decir, la selección y organización de experiencias relevantes y pertinentes que sirvan de apoyo a la comprensión del interlocutor y, por otro, al problema de la gestión de la información, esto es, el manejo de expectativas psicocomunicativas que supeditan la selección de materiales informativos bajo reglas basadas no sólo en las estructuras lingüísticas, sino también, en aquellas con base en la cognición social, que es el área de estudio del procesamiento mental de la información sobre el medio social.

En el modelo propuesto por Tomlin et al. (1997) se explicitan cuatro dimensiones diferentes que, integradas, proporcionan el cumplimiento de los objetivos comunicativos del siguiente modo: a) gestión retórica, que consiste en la representación de una meta discursiva o intención comunicativa y que revela mediante la organización sintáctica los estados de progreso discursivo (Givón, 1992); b) gestión temática, que comporta estrategias cognitivas de multinivel para cumplir con las premisas de aceptabilidad y comprensibilidad subyacentes en la interacción comunicativa en tiempo real, en esta dimensión se organizan los temas y tópicos del discurso, asimismo, dicha organización es una tarea pragmática en la que se toman decisiones online para mantener la centralidad de tal o cual tema y la subordina- 
ción de los referentes que conforman los aspectos periféricos del discurso (Brown y Yule, 1983; Van Dijk, 1980) y que es el objeto de estudio en el presente trabajo; c) gestión referencial, que corresponde a la tarea de selección de aquellos referentes activos para el interlocutor, sea porque se los ha tratado con anterioridad en el discurso o, porque requieren de una introducción, por constituir información nueva. (Dik, cit. en Fernández y Gil, 2000); d) gestión del foco, que alude a los énfasis que el hablante le imprime a determinados referentes, con el fin de que se destaquen sobre el resto de la información que se intercambia.

En este trabajo se analizó la gestión temática como un fenómeno de déficit comunicativo primario. Se revisó la presencia y la gestión de la unidad temática, de los tópicos discursivos y del comportamiento de los vínculos referenciales, en ambos estadios de la patología. Con base en criterios de apreciación cualitativa, logrados gracias a la participación directa de los investigadores en las entrevistas, se operacionalizaron diferentes elementos que le otorgan coherencia y funcionalidad a la interacción para dicha comparación.

Con el fin de comprender las características de los déficit comunicativos presentes en ambos estadios de la esquizofrenia, se comparó el desempeño comunicativo en una entrevista clínica tradicional, tomando en cuenta las restricciones discursivas motivadas por el interés en acceder a la información médica clave. Para optimizar el tiempo de la atención del paciente, los aspectos comunicativos son modelados con el fin de mantener una organización directiva en el intercambio. A fin de evaluar el desempeño comunicativo bajo estas condiciones, se incorporó como tarea base la pregunta acerca del motivo de consulta o de la internación hospitalaria que generalmente se plantea al inicio de la entrevista. Entonces, la respuesta que elaboró el entrevistado corresponde a la composición de un tema general que se analizó en función de los diferentes tópicos desarrollados.

Un punto crucial en este trabajo es el contexto comunicativo que enmarca a la entrevista clínica. Diversos autores coinciden en que, a pesar de contar con la conducción temática del entrevistador, hay un procesamiento disfuncional del contexto pragmalingüístico en la esquizofrenia, siendo ésta una conducta sintomática del desempeño comunicativo en la patología (Chapman, Chapman y Miller, 1964; Manschreck, Maher, Milavetz, Ames, Weisstein y Schneyer, 1988; Spitzer, Weisker, Winter, Maier, Hermle y Maher, 1994; Morice e Ingram, 1983; De Lisi, 2001; Meilijson, Kasher y Elizur, 2004). Otro asunto al que se debió atender fue la pericia del entrevistador, que también jugó un rol en la gestión de la información. A menudo quien entrevista evalúa de manera insuficiente las capacidades informativas del entrevistado y, por ello, realiza exigencias discursivas que sobrepasan su capacidad de gestionar información. Al aumentar las solicitudes de información por turno de habla, el resultado puede ser inversamente proporcional al esperado; por ejemplo, cuando en un turno de habla se incluyen varias preguntas o éstas son complejas, el paciente responderá sólo algunas, eligiendo 
entre aquellas que tiene interés en responder o que le resultan sencillas de abordar, ya sea porque son respuestas monosilábicas o de información específica como, por ejemplo, sus datos demográficos. Este fenómeno sería provocado por las fallas en la memoria de trabajo características del cuadro clínico. Además, la experiencia del entrevistador es muy importante cuando se trata del manejo de pacientes de primer episodio de esquizofrenia o de psicosis, dado que, a causa del proceso psicótico por el que atraviesan, tienden a ser reticentes y poco colaborativos. En virtud de que los profesionales de la salud mental no cuentan con herramientas formativas sobre el lenguaje aplicado a la clínica, con frecuencia se ignoran en la evaluación las consideraciones antes expuestas. A pesar de estas limitaciones, los autores del presente trabajo piensan que analizar fenómenos discursivos generados en situaciones clínicas reales del medio psiquiátrico, facilita la comprensión global de la conducta comunicativa de los afectados en un entorno más natural.

En suma, la situación de interacción discursiva que se aborda presenta reglas, marcos referenciales, estrategias y fenómenos que permiten que sea funcional y susceptible de ser sistematizada a pesar de su dinamismo. Un discurso de base coherente y comprensible sólo se da si hay adecuación de los procesos psíquicos, socioculturales y lingüísticos involucrados; por lo tanto, la competencia comunicativa debe ser evaluada tomando en cuenta todos estos factores que la propician (Hymes, 1996).

\subsubsection{Tema y tópicos del discurso}

Para efectos operativos de este estudio, se entenderá por tema una macroproposición que se elabora a partir de las microestructuras discursivas (Van Dijk, 1980). De igual forma, se entenderá por tópico, una proposición que puede introducir un elemento nuevo en el tema general. A lo largo de la interacción, cada una de las proposiciones que la forman se organizan como cadenas léxico-semánticas y referenciales enlazando los tópicos para establecer poco a poco un asunto general (Gutiérrez Ordónez, 2000).

Las nociones de tema y de tópico han sido ampliamente discutidas generando controversia entre los estudiosos de la lingüística funcional, del análisis del discurso y de la pragmática. Ambos conceptos han sido objeto de diversas orientaciones y abordajes, aunque pareciera que para los especialistas se trata más de diferencias terminológicas que de fondo. Se recogen aquí algunos aspectos que parecen más pertinentes para este trabajo. Siguiendo a Halliday (1994), el tema corresponde al elemento que ocupa la posición inicial en una oración. Por otro lado, también se lo considera como aquella entidad sobre la que se habla, se solicita o se entrega información (Hockett, 1971), de igual manera, se lo concibe como una cuestión de interés inmediato y no reducible a un simple sintagma nominal (Keenan y 
Schieffelin, 1976) o bien, como la información que puede ser fácilmente identificada a partir de la contenida en el contexto (Daneš cit. por Fernández y Gil, 2000). Cercana a esta concepción, se encuentra la explicación de Gutiérrez Ordóñez (2000) acerca de que el hablante procura acotar el marco de validez de sus afirmaciones para alcanzar una optimización en lo que él denomina "la palestra delimitada donde se desarrollan los procesos significados por el verbo y el campo de validez veritativa del enunciado" (Gutiérrez Ordóñez, 2000, p. 40). Parece claro que en la lengua natural el tema también puede desprenderse de la sumatoria de tópicos propuestos; en parte, porque su límite funcional es congruente con unidades lingüísticas de mayor extensión, como el discurso y, en parte, porque entre los miembros de una comunidad de hablantes son compartidos los modelos de representación mental que facilitan la interpretación y reconstrucción del tema del discurso (Van Dijk, 1995).

Por otro lado, el concepto de tópico también ha sido objeto de estudios tipológicos diversos, orientados hacia una clasificación discursiva de los fenómenos pragmáticos que aparecen en el contexto intra o extraoracional, con la consecuente dificultad sobre la que advierten algunos autores; eventualmente pueden coincidir con referentes inactivos que funcionen como focos desde un punto de vista pragmático (Albentosa y Moya, 2001). O bien, pueden vincularse de un modo tangencial con alguno de los temas o tópicos ya introducidos en el discurso, dificultando su identificación referencial (Soto, Hasler y García, 2011). Esta ambigüedad es una de las cuestiones que se esgrime como obstáculo para llegar a un consenso sobre esta noción desde un punto de vista pragmático.

Aquí se tratarán ambos conceptos, tema y tópico, como categorías pragmático funcionales y no gramaticales, puesto que no interesa la estructura informativa de la oración por sí sola (Gutiérrez Bravo, 2008). Una perspectiva funcionalista sustenta la orientación semántico-pragmática que prima por sobre una sintáctica, favoreciendo los principios de aceptabilidad y comprensibilidad indispensables para evaluar la competencia comunicativa. La organización de los elementos que constituyen las expresiones discursivas de los hablantes debe ser evaluada en virtud de las funciones pragmáticas que expresan. Se puede visualizar de qué forma dichas expresiones revelan el estatus informativo y los límites y acepciones que estas expresiones alcanzan, en razón de los diferentes niveles de conocimiento de los hablantes. Dichos márgenes de conocimiento se vinculan a las experiencias propias y al conocimiento sobre los mundos posibles que se comparten en la interacción que está teniendo lugar (Van Dijk, 1995). En este sentido, en cuanto a su función pragmática, el tema y los tópicos suponen un orden y forma distinguibles del resto de la estructura discursiva que pueden estar determinadas incluso por factores como la prosodia y curvas de entonación, como lo señala Escribano (cit. por Gutiérrez Ordóñez, 2000). 


\subsubsection{Matriz analítica}

En este estudio se ha considerado de manera amplia el concepto de tema y de tópico discursivo, debido a que como ya se señaló, el contexto comunicativo de la entrevista clínica presenta límites muy específicos. Se tomarán en cuenta los siguientes fenómenos discursivos para pesquisar y evaluar la gestión temática de los sujetos de la muestra analizada:

1. Unidad temática: el asunto general que hace referencia a la situación de hospitalización o consulta psiquiátrica.

2. Tópicos: contenidos cuya función es incorporar proposiciones que actualicen y organicen la información en el discurso y para este fin se utiliza una serie de recursos que, globalmente, constituyen mecanismos de referencia endofórica o exofórica. En este estudio, se revisarán tres dimensiones de los tópicos discursivos:

2.1. Tópicos desarrollados: las secuencias de oraciones en torno a un referente que presente uno o varios tópicos desarrollados. Estas estructuras pueden aparecer contiguas a las ideas que se desprenden del tema central.

2.2. Saltos topicales: ausencia de contexto introductorio de un nuevo tópico en el discurso. A pesar de que por medio del manejo de mecanismos referenciales se produce un movimiento constante y progresivo, la introducción de un tópico no es informativa por sí sola, es necesario que esa incorporación posea el contexto necesario para su comprensión, cuestión que se verificó en la muestra.

2.3. Interacción entre referentes y vinculos referenciales: la relación entre estas estructuras implica una serie de mecanismos destinados a mantener actualizado el referente. Se establecen relaciones semánticas de base léxica y gramatical, así como recursos de progresión para ir ligando los vínculos y los referentes. Si la distancia que se da entre los vínculos referenciales es muy extensa, el interlocutor debe realizar un mayor esfuerzo para relacionarlos.

A partir del planteamiento de un tema, se imponen reglas de coherencia que deben ser mantenidas por medio de recursos cohesivos para garantizar un intercambio eficaz. Asimismo, el tratamiento que reciben los tópicos en el discurso se rige también por estos principios, de manera tal que, si se cambia un tópico, dicho cambio debe ser gestionado en forma clara para guiar la interacción que permita comprender el tema general.

La red de dependencia entre los enunciados es una forma de actividad mental, en tanto modelo de procesamiento de la información proveniente de la realidad; en consecuencia, se le atribuye una doble dimensión: tanto la relativa al conoci- 
miento de mundo, como la que se simula con el conocimiento representado en el discurso. De esta forma, se espera acceder a la intencionalidad del discurso de los sujetos entrevistados. Los contenidos de una entrevista implican procesar un enorme volumen de información y significados en tiempo real, dificultad sobre la que advierten Brown y Yule (1993) y que se incrementan en personas con dificultades de procesamiento de la información. Se evaluará, por tanto, si la gestión temática se realizó en forma autónoma, con ayuda del entrevistador o fue deficiente.

\section{METODOLOGÍA}

\subsection{Participantes}

Para este estudio se analizó una muestra de 50 entrevistas del corpus: LEnguaje, PSicosis e Intersubjetividad; LEPSI. Este corpus está constituido por entrevistas clínicas grabadas y transcritas, realizadas a personas con diferentes diagnósticos psiquiátricos, en los que predomina la esquizofrenia con un 70\%. Para este estudio se seleccionaron 25 entrevistas realizadas a personas con esquizofrenia crónica $\left(\mathrm{G} 1-\mathrm{CRE}^{2}\right)$ y 25 de primer episodio $\left(\mathrm{G} 2-\mathrm{PEE}^{3}\right)$. Para el grupo de primer episodio se consideraron personas con diagnóstico desde hace menos de tres años al momento de la entrevista ${ }^{4}$. Para el grupo de esquizofrenia crónica se consideraron personas que habían sido diagnosticadas hace más de tres años. El rango de edad de PEE es de entre 14 y 24 años y el de CRE entre 25 y 50 años. El diagnóstico de todos los pacientes incluidos en este corpus y en este estudio fue confirmado por un equipo de psiquiatras, quienes utilizaron la estructura de la entrevista clínica para el DSM-IV (1997) y la escala de síntomas positivos y negativos PANSS (Kay, Opler, Spitzer, Williams, Fiszbein y Gorelick, 1991). Todos los pacientes incluidos en este estudio estaban estabilizados psicopatológicamente, recibiendo dosis orales o de depósito de antipsicóticos, por espacio mínimo de un mes. En el caso de los PEE, además estaban insertos en el programa AUGE5 5 . La participación para este estudio contó con un consentimiento informado escrito firmado por los pacientes y un familiar o cuidador responsable. A pesar de que no figura dentro de los objetivos de este trabajo, es necesario realizar un alcance con respecto a las diferencias sociodemográficas entre ambos grupos de pacientes. En psiquiatría, variables como los años de estudios alcanzados o el grupo socioeconómico al que pertenecen los afectados ${ }^{6}$ no se estudian como factor exclusivo del impacto de la

\footnotetext{
${ }^{2}$ G1-CRE: Grupo 1 - crónico de esquizofrenia.

${ }^{3}$ G2-PEE: Grupo 2 - primer episodio de esquizofrenia.

${ }^{4}$ Guía MINSAL para el manejo del primer episodio de esquizofrenia.

${ }^{5}$ AUGE: Acceso Universal a Garantías en Salud.

${ }^{6} \mathrm{Se}$ desconocen datos censales precisos sobre la incidencia de los años de escolaridad o grupo so-
} 
enfermedad. Resulta obvio que los factores sociodemográficos como éstos representan una importante arista que puede contribuir a mejorar la calidad de vida, sin embargo, las iniciativas para la cobertura de la salud mental en Chile priorizan la detección precoz y la adherencia al tratamiento psiquiátrico desde el primer episodio por sobre otros factores.

Como grupo control, se incluyeron 12 entrevistas del corpus ESECH, Estudio Sociolingüístico del Español de Chile, que es un grupo de estudio del Departamento de Lingüística de la Universidad de Chile (San Martín y Guerrero, 2015). Estas entrevistas fueron aplicadas a personas sin diagnóstico psiquiátrico, pareadas por edad, sexo y características sociodemográficas, con el resto de los participantes. En la Tabla I se reseñan las características de todos los participantes:

Tabla I. Datos demográfico-clínicos de los participantes.

\begin{tabular}{|c|c|c|c|c|c|c|c|c|c|}
\hline \multirow[t]{3}{*}{ GRUPOS } & \multirow[t]{3}{*}{$\mathrm{n}$} & \multicolumn{2}{|c|}{ Sexo } & \multicolumn{2}{|c|}{ Años/escol } & \multicolumn{4}{|c|}{ Ocupación } \\
\hline & & \multirow[t]{2}{*}{$\mathrm{H}$} & \multirow[t]{2}{*}{$\mathrm{M}$} & \multirow[t]{2}{*}{8} & \multirow[t]{2}{*}{12} & \multirow[t]{2}{*}{$\begin{array}{c}\text { Actividad } \\
\text { remunerada }\end{array}$} & \multicolumn{3}{|c|}{$\begin{array}{l}\text { Sin actividad } \\
\text { remunerada } *\end{array}$} \\
\hline & & & & & & & 1 & 2 & 3 \\
\hline G1-CRE & 25 & 13 & 12 & $100 \%$ & $84 \%$ & $12 \%$ & $80 \%$ & $8 \%$ & $0 \%$ \\
\hline G2-PEE & 25 & 14 & 11 & $100 \%$ & $12 \%$ & $20 \%$ & $28 \%$ & $0 \%$ & $52 \%$ \\
\hline G3-CON & 12 & 6 & 6 & $100 \%$ & $80 \%$ & $45 \%$ & $13 \%$ & $20 \%$ & $22 \%$ \\
\hline TOTALES & 62 & 33 & 29 & & & & & & \\
\hline
\end{tabular}

*(1)Sin Trabajo, (2)Dueña/o de Casa, (3)Estudiante.

\subsection{Procedimiento}

\subsubsection{Esquema operativo}

El esquema operativo del presente estudio comprendió una selección aleatoria de las entrevistas clínicas del corpus LEPSI. Luego se identificaron y analizaron los temas y los tópicos desplegados en ellas. En lo que sigue se realizó el procesamiento estadístico descriptivo de los datos y la interpretación de los resultados.

Se aplicó una valoración del desempeño comunicativo eficaz en la entrevista, basado en tres niveles de elaboración por parte del entrevistado. Estos niveles de

cioeconómico y la enfermedad en nuestro país. Según las cifras aportadas por el INE y el MINSAL, los chilenos con discapacidades psiquiátricas generales bordean un $8 \%$ y dentro de este porcentaje estarían contenidos quienes presentan diagnóstico de esquizofrenia. 
valoración fueron sometidos al juicio de seis expertos del área de lingüística y psiquiatría, quienes procedieron a evaluar el instrumento mismo aplicándolo a muestras de habla del corpus LEPSI. En virtud de la validez y fiabilidad de los criterios evaluados, coincidieron en el siguiente etiquetado (Tabla II): N3 (adecuado), responde desarrollando satisfactoriamente el tema y sigue la topicalización propuesta por el entrevistador o por sí mismo; N2 (con ayuda), requiere apoyo del entrevistador para esclarecer el significado propuesto, ya sea reiterándole la pregunta o reformulándosela, modelamiento tras el cual es posible comprender parcial o completamente las respuestas; y N1 (falla completa), a pesar de la ayuda del entrevistador no logra desarrollar ni el tema general, ni la topicalización propuesta. En este caso, las fallas en la elaboración de las respuestas o participación comunicativa, sólo permiten una comprensión en extremo fragmentaria del discurso.

Tabla II. Niveles de valoración del desempeño comunicativo en la entrevista.

\begin{tabular}{|l|l|c|}
\hline \multicolumn{3}{|c|}{$\begin{array}{c}\text { Niveles de desempeño en la tarea comunicativa de explicar los motivos } \\
\text { de la consulta u hospitalización. }\end{array}$} \\
\hline N 3 & $\begin{array}{l}\text { Responde desarrollando satisfactoriamente el tema y/o sigue la } \\
\text { topicalización propuesta por el entrevistador. }\end{array}$ & Adecuado \\
\hline N 2 & $\begin{array}{l}\text { Requiere ayuda del entrevistador para esclarecer el significado } \\
\text { propuesto, ya sea reiterándole la pregunta o reformulándose- } \\
\text { la, modelamiento tras el cual es posible comprender parcial o } \\
\text { completamente las respuestas. }\end{array}$ & Con ayuda \\
\hline N 1 & $\begin{array}{l}\text { A pesar de la ayuda del entrevistador, no se logra desarrollar ni } \\
\text { el tema ni la topicalización y las fallas en la elaboración de las } \\
\text { respuestas sólo permiten una comprensión fragmentaria. }\end{array}$ & Falla completa \\
\hline
\end{tabular}

El diseño de este estudio es transversal, comparativo y no experimental. En lo que se refiere a la descripción del procedimiento estadístico utilizado, se realizó un análisis discursivo de las entrevistas transcritas, a partir del cual se generaron variables que fueron categorizadas. De esta forma, al tratarse de un estudio con variables cuantitativas múltiples, se comprobó la distribución normal de los datos conseguidos y se utilizó una prueba no paramétrica, $c h i$ cuadrado, que sirvió para correlacionar la presencia o ausencia de algunas variables con factores como el estadio de la enfermedad y el sexo de los participantes. En todos los casos, el grado de significación estadística se definió en $\mathrm{p}=<0.05$. El paquete estadístico utilizado es el SPSS (Statistical Package for the Social Sciences), versión 21 para Windows. 


\section{PRESENTACIÓN Y ANÁLISIS DE LOS RESULTADOS}

\subsection{Consideraciones previas}

Con el fin de diferenciar el desempeño comunicativo entre el grupo de personas con patología crónica y el de primer episodio, los datos obtenidos están organizados en diferentes niveles de observación que pueden aportar evidencia convergente: i) en términos descriptivos, según frecuencias absolutas y porcentajes de frecuencia de las variables estadio y sexo; ii) en términos cualitativos, en relación con la eficacia comunicativa lograda por los participantes del estudio en ambas variables.

A continuación se presentan tres ejemplos de dificultades en el manejo temático en el grupo de crónicos y de primer episodio, además de ejemplos del grupo de control; posteriormente, se revisarán los porcentajes de frecuencia de algunas variables y se intentará responder las preguntas que sirvieron de base para este estudio.

\subsection{Función pragmático-discursiva de la gestión temática}

\subsubsection{Tema}

\subsubsection{Unidad temática-falla completa (UT-N17)}

El siguiente ejemplo corresponde al inicio de la entrevista desde el primer turno de habla. Fue realizada a un paciente crónico, de sexo masculino. Como se puede apreciar, es el paciente el que inicia la entrevista, proponiendo un tema que es: <yo quiero decirles mi...//parte de mi vidals. Sin embargo, a pesar de esta ventaja, no es posible extraer un tema central fuera del enunciado que lo enmarca como punto de partida; las innumerables pausas extensas se suman a la multiplicidad de fragmentos temáticos enunciados que dificultan el seguimiento del tema. Por efectos de espacio no se incluyó el turno de habla completo que se extiende por varios minutos con resultados idénticos al fragmento aquí expuesto. Se realizó una transcripción ortográfica de las entrevistas y se incluyeron las siguientes etiquetas propuestas por Gallardo Paúls en el corpus PErLA ${ }^{8}$.

\footnotetext{
${ }^{7}$ UT-N1: Unidad temática - Falla completa (N1).

${ }^{8}$ PErLA: Percepción, Lengua y Afasia, corpus de datos clínicos de la Universidad de Valencia.
} 
Ejemplo 1. Unidad temática en CRE9.

UT-N1 (1) S: bien/ ¿̇ah?/ ¿cierto?// sí// bueno yo me llamo X/ espero que nos llevemos bien hoy día/ para que tengamos un día feliz (5.0) eh (5.0) yo quiero decirles mi (5.0) parte de mi vida/ es que puedo darme cuenta de toda la realidad concreta/ que nos hace mejores / cuando nace un hijo / de una pareja/ innato/ conciencia innato/ o sea conciencia/ y lo otro/ género humano / de la parte congenia/ congenia/ congénito/ ¿̨cierto? / viene más allá de innato/ congénito/ eh (5.0) viene del verbo mental como proceso/ la verdad// va por hecho/ lo congénito / somos capaces de discernir el bien del mal/ para después tener conciencia de saber una/ una esencia del bien / lo / para manejar / el comportarse con influencias definitivas del mundo/ $[\ldots]$

En el siguiente ejemplo (PEE) se aprecia el mismo fenómeno que en el Ejemplo 1, de no contar con información contextual sobre su caso, es difícil suponer que no se trata de un paciente crónico. La elaboración de la información por parte del entrevistado es enrevesada y poco informativa, marcada por las frecuentes pausas, vacilaciones, enunciados incompletos y utilización excesiva de fórmulas de atenuación: como quel pero igual.

Ejemplo 2. Unidad temática en PEE.

UT-N1 (2) E: hola/ hola/ ¿cómo está?/ ¿por qué viene X?

S: vengo porque// estoy tratando que/ para que/ como que// como que// como que viera que/ no estaría mal/ pero igual/ mi mamá dice que nunca fue así y yo / ehmmm (5.0) me gustaría saber si/ eh (5.0) no sé (5.0) si creerle o no porque $\mathrm{X} /$ también/ mi primo/ me dijo/ algo como raro/ como que en un momento si/ y después como que no (5.0)

\subsubsection{Tópicos}

\subsubsection{Tópicos desarrollados - falla completa (TD-N1 $\left.1^{10}-N 2^{11}\right)$}

El Ejemplo 3 fue tomado de un paciente crónico de sexo masculino con múltiples hospitalizaciones por baja adherencia a los tratamientos. El entrevistador propone

${ }^{9}$ Con el fin de facilitar la lectura y comprensión de los ejemplos, hemos incluido solo algunas etiquetas que se utilizan para marcar, pausas, énfasis y otros elementos discursivos fueron considerados en el análisis de los datos:

Anotaciones corpus PERLA:

/ Pausa corta, de menos de medio segundo

// Pausa que oscila entre medio segundo y un segundo

/// Pausa de un segundo de duración

(5.0) Pausa extensa de cinco segundos o más

${ }^{\circ}()^{\circ}$ Pronunciación en voz muy baja, próxima al susurro.

${ }_{10}$ TD-N1: Tópico desarrollado y Falla completa (N1).

${ }^{11}$ TD- N2: Tópico desarrollado - con ayuda (N2). 
un tópico -evaluación personal sobre su estancia en el servicio de psiquiatría-, el paciente no sigue la topicalización propuesta y señala otro tópico que en forma tangencial puede vincularse al propuesto por el entrevistador. Se puede interpretar que quiere salir del hospital porque tiene responsabilidades que cumplir como el cuidado de sus mascotas. Sin embargo, la interpretación puede dirigir a un significado alejado de la intención del entrevistado, por tanto, hay que observar si existen evidencias concretas en esta cadena referencial. Se cuenta con un enunciado inicial que funciona como tópico introductorio: < ese neoprén estuve averiguando unas cosas $>$, reforzado por su aclaración: < que son los detalles para salirl> pero que no se desarrolla posteriormente ya que el paciente introduce elementos independientes como <no existe la espada del augurio/>, que tampoco se vincula con el siguiente enunciado: <esos son perros/los tengo que alimentar/>. Este enunciado que se inicia con el deíctico esos, no considera el conocimiento compartido con el interlocutor, pues el entrevistado asume que su referencia es clara.

Ejemplo 3. Tópico desarrollado en CRE.

TD-N1 (3) E: ¿Cómo se ha sentido aquí en el hospital?

S: ese neoprén estuve averiguando unas cosas/ que son los detalles para salir/ no existe la espada del augurio/ esos son perros los tengo que alimentar/ lo que dije/ significa tengo que solventarme/ ya que nadie me solventa/ y tengo que solventar a mis mascotas/mis mascotas no me van a protegerme nunca, entonces acabo de alimentar a mis mascotas y ahora tengo que congelarlas a todas.

En el Ejemplo 4 el entrevistador propone un tópico que da inicio a una adecuada cadena referencial por parte de la entrevistada. Sin embargo, tras la primera pausa extensa: <no hablaba>// <tenía // muy poco contacto sociall// se produce una mayor laxitud entre los elementos que componen esta cadena referencial, complicando el significado de la respuesta elaborada por la paciente. Aunque es posible comprender de manera aproximada que su hospitalización fue causada porque había dejado de establecer contacto con otras personas, no queda clara la relación entre: <no hablaba dellbueno/ nadie // no me gustaba que me vieran feal ese era el tema.

Ejemplo 4. Tópico desarrollado en PEE.

TD-N2 (4) E: ya / ¿y por qué la hospitalizaron?

S: por / otras cosas / me hospitalizaron porque/ no tenía / no hablaba /// tenía/// tenía muy poco contacto social (5.0) no era que no hablaba / o sea /// no hablaba con nadie/ o / en realidad/ no salía de mi casa/ porque/ <alargamiento $>/ / /$ eh///<alargamiento>/cuando hablaba/// no más/ ¿por qué era?/<se pregunta a si misma $>$ / ahora ya no lo tengo/ si/ porque / no/ no hablaba de//bueno/ nadie//no me gustaba que me vieran fea/ ese era el tema>/ 


\subsubsection{Salto topical - falla completa (ST-N1 $\left.1^{12}-N 2\right)$}

Los saltos topicales no aparecen entre los informantes del grupo control y operan de forma similar en ambos estadios de la enfermedad, aun cuando fueron evidentes entre el grupo de personas con patología de larga evolución. Sin duda, constituye un indicador muy informativo del estado de planificación y monitoreo de la información efectuado por los pacientes, y el hecho de aparecer en el primer episodio es señal de un probable deterioro cognitivo precoz.

En el Ejemplo 5 se puede observar que el entrevistador plantea una pregunta directa para modelar la atención del paciente hacia un tópico que no ha explicitado de manera satisfactoria. No obstante, la respuesta del entrevistado no entrega información que permita aclararlo pues incorpora otros tópicos inconexos e incluso algunos neologismos que no contribuyen de manera alguna al seguimiento de la topicalización propuesta por el entrevistador. Éste es un ejemplo de cómo se dificulta la interacción entre una persona con esquizofrenia crónica y un hablante sin esta patología psiquiátrica.

Ejemplo 5. Salto topical en CRE.

ST-N1 (5) E: cuéntenos un poco acerca de la milicia/ ¿en qué consiste eso de la milicia?>/ S: en ir pa <ra allá/ y hacerse el soberbonante/ y hacerse la chiconaniquetante, / consiste /mi vida en ser insistentene/ porque yo no veo televisión/ y nunca he visto la televisión/ ahora estoy viendo programas regrabados/ y el cable no se desgrava/ no se desgrababa, /ni se se desgrobosoba, / se pasteliban y mi robot la aplastó /// pa $<$ ra $>$ que se haga la luz y la electricidad///

En el Ejemplo 6 el entrevistador utiliza algunas estrategias discursivas que operan como marcas directas para lograr que la paciente se concentre en el contexto temático que le proporciona: $<E$ : a ver/ ya / pero yo le pregunto por otra cosa / ¿cómo es eso de que la miran fea? </cuénteme eso>; < ¿a qué se refiere con: "no me gustaba que me vieran fea"?/> El éxito de la aplicación de estas estrategias es relativo, pues se accede con dificultad al significado de la respuesta en virtud de una selección -que debe hacer el interlocutor- de los elementos informativos pertinentes para este contexto. La paciente introduce una serie de tópicos que no guardan relación con el tópico introducido al inicio; además, al no estar enlazados operan como distractores, por ello se evaluó este desempeño como N2, con ayuda del entrevistador.

${ }^{12}$ ST-N1: Salto Topical - falla completa (N1). 
Ejemplo 6. Salto topical en PEE.

ST-N2 (6) E: ¿Por qué no le gustaba que la vieran fea? I

S: si/ pero/ eso no tiene nada que ver con la tristeza ese era un tema mío / separado/ totalmente separado.

E: a ver/ ya / pero yo le pregunto por otra cosa / ¿cómo es eso de que la miran fea? $</$ cuénteme eso.

S: la tristeza era cuando pensaba/

E: $\mathrm{mmm} /$ pero/ yo le pregunto por lo que usted me dijo/ eso de que no le gustaba que la vieran fea/¿qué gente es esa?

S: no/ me gustaba que (5.0) que las otras personas me vieran/ es que yo para salir/ solamente/ podía salir contando con cierto/ con cierta imagen/ en todas las cosas me acuerdo de / me acuerdo un poco/// ¿̇o no era un poco de la playa? / no es que quiera tener / una/// o más delgada / más linda/ más delgada / como no podía conseguir estar más delgada y más linda / no salía de mi casa.

E: ya<pausa $>$ ¿qué gente era esa?!

$S:$ es que lo delgada/ quería eso/

E: $\mathrm{mmm} /$ ¿pero la gente se daba cuenta de eso?/ ¿a qué se refiere con: "no me gustaba que me vieran fea”?/ eso le pregunto/ ¿tenía alguna preocupación la gente hacia usted?

$S$ : no <pausa $>$ / en realidad <pausa $>$ / cualquier persona que me viera fea afuera $<$ pausa $>$ / en la calle.

\subsubsection{Interacción entre vínculos y referentes y falla completa (IVR-N1 $\left.1^{13}\right)$}

En el Ejemplo 7 el entrevistador también propone un marco referencial para desarrollar. En este caso, se cuenta con una muestra correspondiente a un paciente que cursó hasta tercer año de universidad y que con frecuencia incorpora algunos elementos léxicos tomados de su área de estudio que interfieren a veces con su manejo de la información. El paciente elabora una cadena de referentes inconexos que además de no responder al requerimiento informativo del entrevistador, no se desarrollan de forma efectiva.

Ejemplo 7. Interacción entre vínculos y referentes en CRE.

IVR-N1 (7) E: ¿se siente mejor?/ ¿contento?

S: El sit <sic> se come al error/el ser a estar/ estar a sentir/ el sentir es un verbo/ compatibilización/ es lo que más vale en el mundo/// alt/más/

E: pero/ ¿̇en qué ha mejorado?

S: en la sinapsis/ porque en la sinopsis/// es un compendio.

E: $\mathrm{mmm}$

En el Ejemplo 8 se establecen redes semánticas con asociaciones laxas que invisibilizan la relación cohesiva entre los referentes. Frente a la pregunta: $<E: \mathrm{mmm} /$

${ }^{13}$ IVR-N1: Interacción entre vínculos referenciales - falla completa (N1). 
pero cuénteme cómo se inicia su problemal>, el paciente incorpora algunas marcas temporales como: <y después//I antes de eso / o sea luna vez>, para agregar: <yo habia visto una pecosa $>$. Al final del turno, el paciente proporciona información que resulta relevante para comprender su actual situación: $<y$ me hablan hartas personas// o seal mentalmente $>$, pero accedemos a ella sorteando todos los elementos discursivos irrelevantes. Además, las pausas extensas añaden un distractor adicional, ya que no presentan las características canónicas descritas en el análisis de la conversación. Levinson (1983) señala que se producen silencios extensos frente a información no prioritaria, maximizándose los espacios vacíos (Gallardo Paúls y Valles, 2008), además de provocarse una interrupción en el flujo discursivo que se torna difícil de reparar.

Ejemplo 8. Interacción entre vínculos y referentes en PEE.

IRV-N1 (8) E: mmm/ pero cuénteme ¿cómo se inicia su problema?/

S: y después (5.0) antes de eso / o sea /una vez/ yo había visto una pecosa ///en La Florida en el 14 de Vicuña Mackenna*//en Cabildo/ en el Lider**/ o sea/ no me acuerdo/ o yo la vi como cuatro veces /ya /// después pasó ese tiempo y pasó lo que dije hace poquito//y me hablan hartas personas//o sea/ mentalmente

E: pero// ¿a usted esta persona es la que le habló?/

S.: (5.0) la vi hartas veces/

E: pero / ¿ella le hablaba?/ ¿ella era la que le hablaba a usted mentalmente?

S: (5.0)la vi /// amiga de un vecino///pecosa

*[Avenida principal de la comuna La Florida, que tiene una ubicación geográfica sur poniente en Santiago de Chile].

** [supermercado].

Finalmente, y para contrastar los ejemplos anteriores, se presentan tres fragmentos que corresponden a personas sin esta patología. En primer lugar, ninguna de ellas presentó pausas extensas o silencios que obstruyan el flujo informativo. La unidad temática es pesquisable y se mantiene, cumpliendo el objetivo comunicativo de forma satisfactoria. En el tópico que propone el entrevistado se presenta un adecuado desarrollo referencial que facilita el seguimiento del tema: <tuve un sueño $>$, la utilización de: <habrá si[d]o premonitorio $>\mathrm{y}<$ soñé variah nocheh con ella $>$, así como de: <soñaba con ella >, permiten cohesionar los elementos empleados para comprender la cadena referencial: [sueño premonitorio con la muerte de la madre de un amigo]. Únicamente pesquisamos dos casos de saltos topicales, fenómeno que al igual que los errores como palabras cortadas o vacilaciones no incidieron en la comprensión de la entrevista de los informantes. 
Ejemplos en CON.

\begin{tabular}{|c|c|c|}
\hline UT-N3 & (9) & 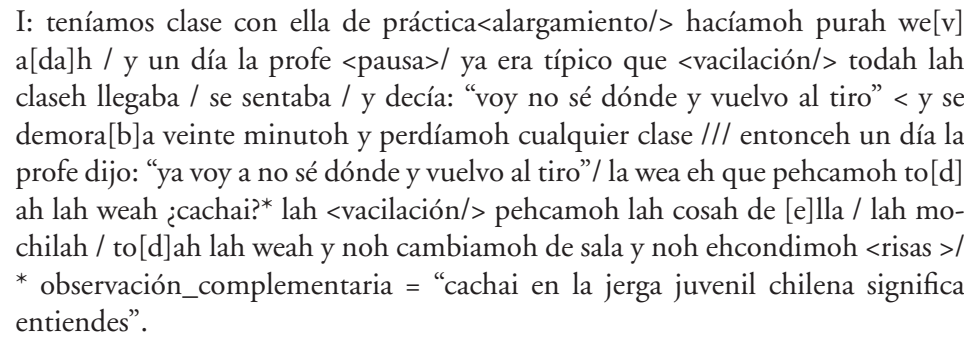 \\
\hline TD-N3 & (10) & $\begin{array}{l}\text { I: tuve un sueño / no sé si habrá si }[\mathrm{d}] \text { o premonitorio pero <alargamiento/> } \\
\text { anteh que se muriera la mamá de una amiga / yo soné variah nocheh con ella } \\
\text { / como }<\text { vacilación/> no }<\text { vacilación/ } / \text { no que se }<\text { vacilación/ } / \text { que se fuera a } \\
\text { morir sino que soñaba con ella to }[\mathrm{d}] \text { oh loh díah no sé conversando <alarga- } \\
\text { miento/> haciendo cualquier cosa/ y dehpuéh / doh díah dehpuéh me entero } \\
\text { así que }<\text { alargamiento/ }<<\text { vacilación/ } />\text { que se murió }\end{array}$ \\
\hline ST-N2 & (11) & $\begin{array}{l}\text { I: yo lo apoyaría / pero<alargamiento/> preferiría que se casaran } \\
\text { E: ¿sus hijos? } \\
\text { I: el respeto que he tenido yo } \\
\text { E: mmm } \\
\text { I: pero si no se quieren casar / lo apoyaría a los dos siempre cuando estuvieran } \\
\text { de acuerdo los padres de ella también }\end{array}$ \\
\hline IRV-N3 & (12) & $\begin{array}{l}\text { I: mmm <silencio/> cuando ehtábamoh en enseñanza media / me acuerdo que } \\
\text { era <énfasis }>\text { súper </énfasis }>\text { peliadora / y que me decían Martín Vargas/ y que } \\
<\text { alargamiento/> siempre andábamoh rompiendo lah cosah que hacían en arteh } \\
\text { pláhticah/ eso siempre me acuerdo } \\
\text { E: ¿y te agarrabai a comboh o no?/ } \\
\text { I : <énfasis > sí po / si me agarraba a comboh </énfasis > pero porque era mujer } \\
\text { no me pegaban loh hombreh po } \\
\text { E: ah obvio } \\
\text { I: pero con lah mujereh me agarraba // <risas }>\end{array}$ \\
\hline
\end{tabular}

\subsection{Indicadores y variables significativas}

En esta sección se exponen los resultados del estudio en cuanto a la relación entre los indicadores de gestión temática y las dos variables extralingüísticas consideradas en el análisis: estadio de la enfermedad y sexo de los sujetos de la muestra.

\subsubsection{Estadio de la enfermedad}

Es posible verificar que en el grupo de las personas con patología crónica se observa deterioro en los cuatro fenómenos de gestión temática en mayor o menor grado y en el grupo de personas con primer episodio se advierte una mayor necesidad de 
apoyo del entrevistador para el logro de los objetivos comunicativos.

El indicador unidad temática presenta un porcentaje mayor entre el grupo de CRE en el nivel adecuado con 11 casos (44\%), en cambio los informantes del grupo de PEE alcanzan un porcentaje menor, con 6 casos (24\%). Por las características clínicas de la muestra de crónicos empleada (exclusión de agudos), la diferencia en el desempeño puede explicarse a partir de la estabilización de más larga data de los pacientes en esta etapa en comparación con los de PEE, por lo tanto, no es infrecuente que refieran con mayor eficiencia los aspectos relacionados con su proceso mórbido, situación que además han realizado en mayor número de oportunidades. En el indicador unidad temática en el primer episodio se presenta una mayor prevalencia del nivel con ayuda para conseguir mantener la unidad temática, en contraste con el requerimiento de las personas del grupo de crónicos, comportamiento que puede explicarse a partir de las evidencias descritas en la literatura acerca de los déficit en atención sostenida y funciones ejecutivas de las que depende la planificación de la información entre las personas con esquizofrenia de primer episodio, información representada en el Gráfico 1. Por otro lado, falla completa en porcentajes equivalentes en ambos grupos de participantes (CRE $=50 \%$, PEE=50\%); esto podría indicar dificultades similares en el control inhibitorio de información irrelevante y en la planificación discursiva general. El grupo control no presentó ninguna falla en la elaboración de la unidad temática. El valor de chi cuadrado es de 19,482 ( $\mathrm{p}<0.01$ ), significativo estadísticamente.

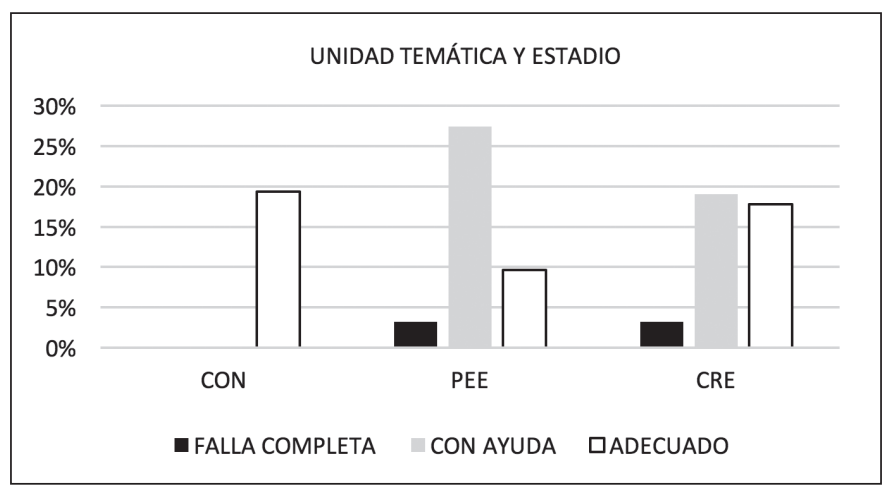

Gráfico 1. Desempeño en UT y estadio de la enfermedad.

En cuanto a los tópicos con desarrollo, se observaron más dificultades en el grupo de personas con patología crónica: la presencia de falla completa (CRE=100\%). No obstante, en el primer episodio (PEE) se presentó un porcentaje importante del nivel con ayuda para desarrollar la continuidad de tópicos discursivos, lo que implica que este indicador de gestión temática también se encontraría comprometido. Dicha información está representada en el Gráfico 2. El grupo control no 
presentó ninguna falla en la elaboración de tópicos con desarrollo. El valor de chi cuadrado es de 20,639 ( $\mathrm{p}<0.01$ ), significativo estadísticamente.

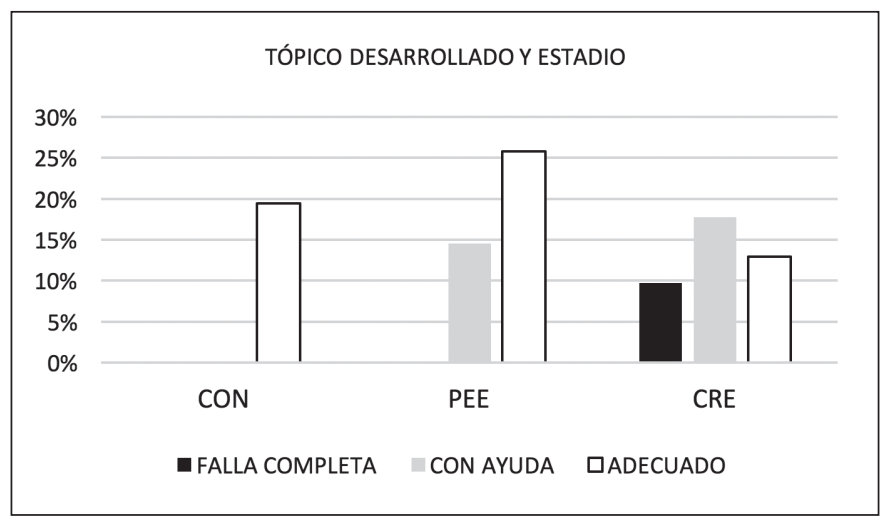

Gráfico 2. Desempeño en TD y estadio de la enfermedad.

En el estadio crónico se observa una marcada presencia del indicador saltos topicales con el $100 \%$ de las ocurrencias en falla completa $(\mathrm{CRE}=100 \%)$. Para mantener la topicalización propuesta, en el estadio de primer episodio se manifestó una mayor prevalencia del nivel con ayuda. Esto podría explicarse porque en el primer episodio aún se responde al contacto intersubjetivo como apoyo a la estructuración discursiva; sin embargo, en el estadio crónico se aprecia un mayor deterioro en estas funciones. Dicha información está representada en el Gráfico 3. Éste es el único indicador en el que se encontraron dos casos del nivel con ayuda, en el grupo control. El valor de chi cuadrado es de 17,958 ( $<<0.01$ ), significativo estadísticamente.

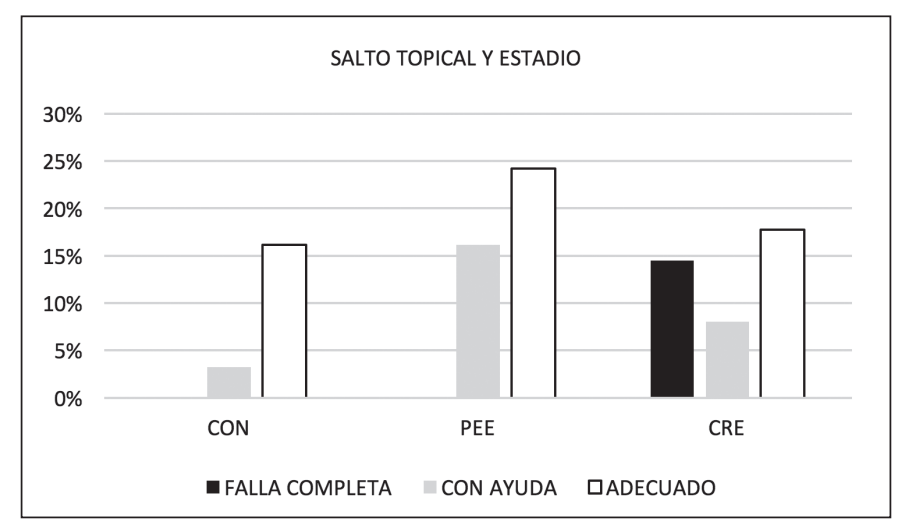

Gráfico 3. Desempeño en ST y estadio de la enfermedad. 
En el indicador interacción de vinculos y referentes, hubo una mayor presencia de falla completa en el grupo de crónicos $(\mathrm{CRE}=48 \%)$, pero también se presentó entre las personas del grupo de primer episodio $(\mathrm{PEE}=24 \%)$. Asimismo, son elevados los porcentajes del nivel con ayuda en ambos estadios, información representada en el Gráfico 4. El grupo control no presentó ninguna falla en la elaboración de interacción de vínculos y referentes. El valor de chi cuadrado es de 21,352 ( $\mathrm{p}<$ 0.01 ), significativo estadísticamente.

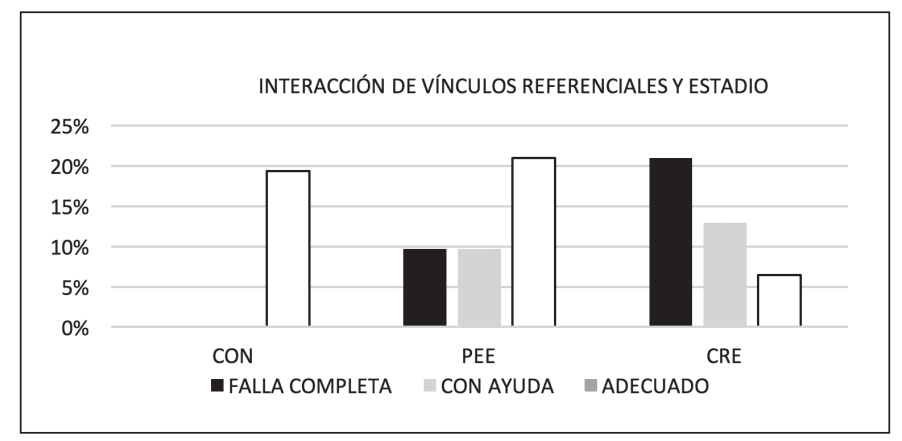

Gráfico 4. Desempeño en IVR y estadio de la enfermedad.

\subsubsection{Sexo}

Tradicionalmente, la variable sexo ha sido descrita por la literatura especializada como homogénea, en consecuencia, no significativa en la comparación entre ambos estadios. No obstante, estudios recientes han cuestionado esta homogeneidad, tomando factores como la edad de inicio de la enfermedad, en cuyo caso los hombres presentarían en su mayoría un inicio más precoz que las mujeres. Sumado a esto, también han surgido evidencias de que las mujeres presentarían un mejor funcionamiento premórbido, además de una evolución más favorable en el largo plazo (Usall, 2003). En este estudio, pese a que no se encontraron resultados significativos estadísticamente, se observó que las mujeres presentaron un desempeño mejor que el de los hombres del corpus, lo que puede constituir un factor cualitativo de interés clínico.

En el indicador unidad temática no se presentaron diferencias entre hombres y mujeres en falla completa $(\mathrm{H}=50 \%$ y $\mathrm{M}=50 \%)$. El valor de chi cuadrado es de ,245 (p, 885>), no significativo estadísticamente. 


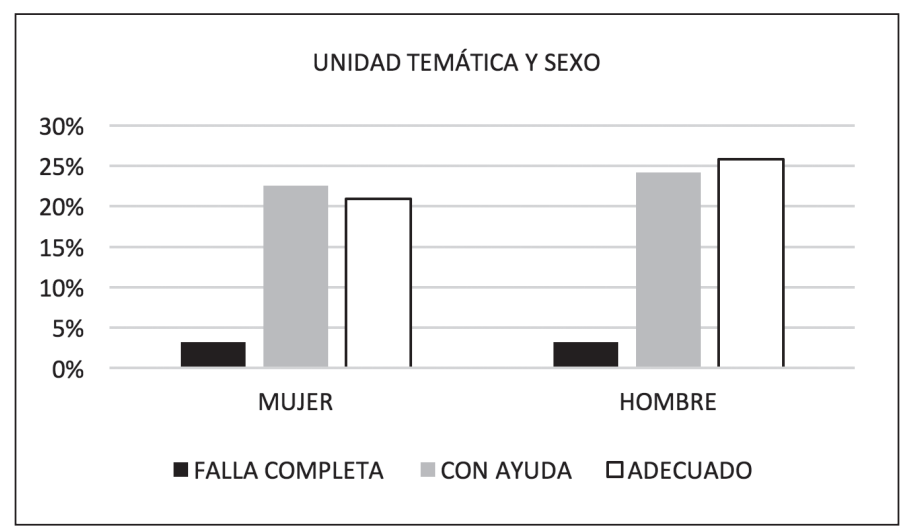

Gráfico 5. Desempeño en UT y sexo.

En el indicador tópicos con desarrollo se observaron seis casos de falla completa. A pesar de que se observó una mayor incidencia en hombres respecto a las mujeres, no se encontraron resultados significativos $(\mathrm{H}=83 \%$ y $\mathrm{M}=16 \%)$. El valor de chi cuadrado es de 2,731 a (>p, 255>), no significativo estadísticamente.

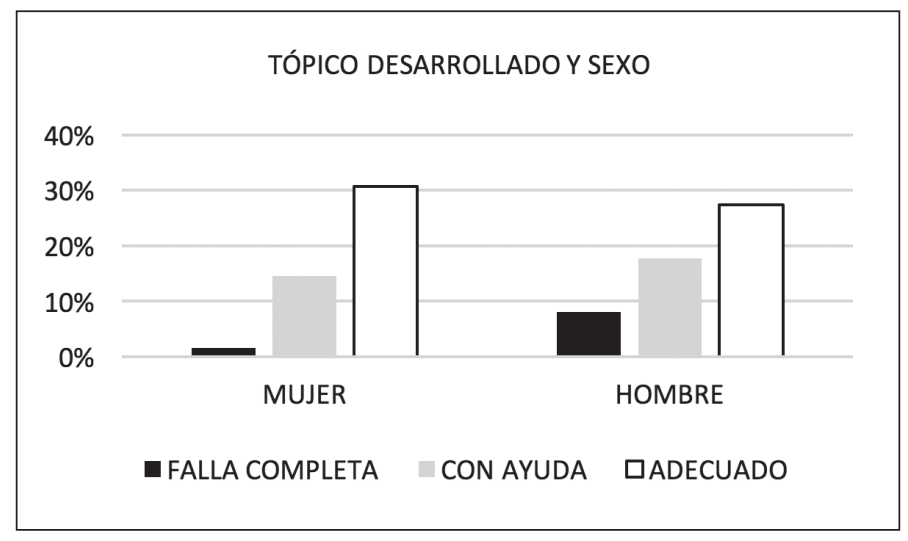

Gráfico 6. Desempeño en TD y sexo.

En la presencia de saltos topicales, se observaron nueve casos de falla completa. A pesar de que se observó una mayor incidencia en hombres respecto a las mujeres, no se encontraron resultados significativos ( $\mathrm{H}=77 \%$ y $\mathrm{M}=22 \%)$. El valor de $c h i$ cuadrado es de $3,697^{\mathrm{a}}(>\mathrm{p}, 157>)$, no significativo estadísticamente. 


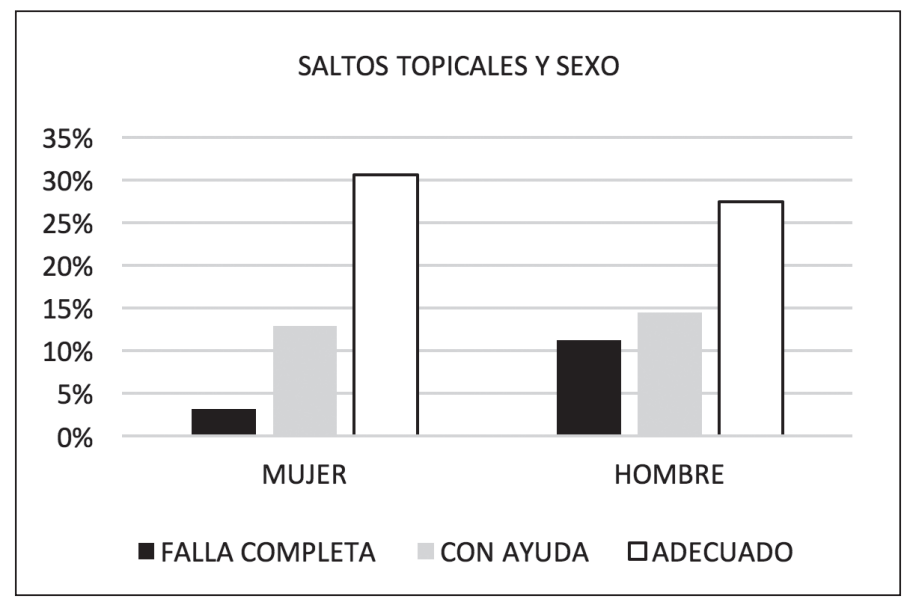

Gráfico 7. Desempeño en ST y sexo.

Finalmente en la interacción de vínculos y referentes, se observaron 19 casos de falla completa. A pesar de que se observó una mayor incidencia en hombres respecto a las mujeres, no se encontraron resultados significativos ( $\mathrm{H}=44 \%$ y $\mathrm{M}=36 \%$ ). El valor de chi cuadrado es de 1,349a ( $\mathrm{p}<509)$, no significativo estadísticamente.

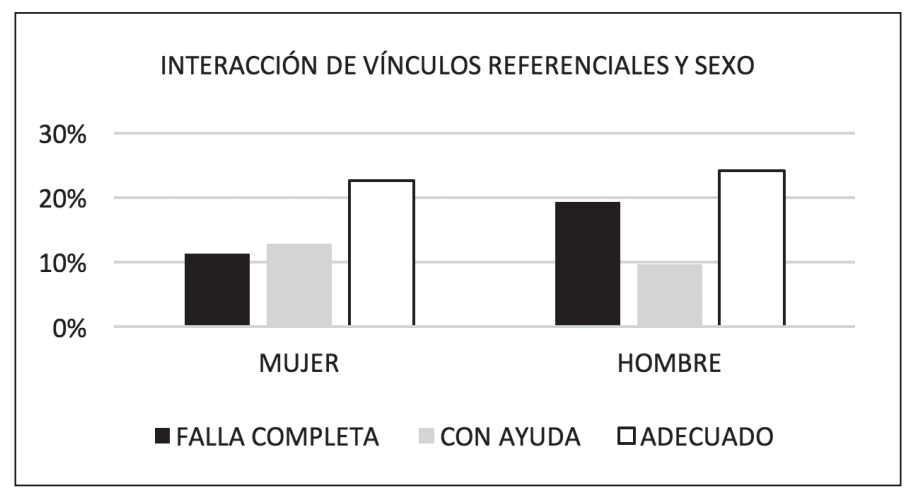

Gráfico 8. Desempeño en IVR y sexo.

\section{DISCUSIÓN}

La larga data del estudio del lenguaje en la esquizofrenia ha provisto de una amplia variedad de abordajes del problema. A nuestro juicio, los que exploran los roles pragmático-discursivos en la interacción sobresalen en rendimiento. La comprensión integrada de la enfermedad es uno de los objetivos más relevantes para la psi- 
quiatría y, en este sentido, la lingüística clínica supone una contribución directa. Estudios como los de Chaika y Lambe (1985); Piro (1987); Chapman y Chapman (1987) o Belinchón (1988), entre muchos otros, sentaron las bases sobre las características de dicha interacción y enfatizaron la observación de las habilidades comunicativas conservadas de los pacientes. No obstante, la sistematización del perfil comunicativo en este contexto no se ha conseguido del todo. Por otra parte, su estudio en el primer episodio continúa siendo desconocido. Por ello, la indagación en estructuras como la gestión temática en la interacción constituye un acercamiento relevante al problema del déficit comunicativo en la esquizofrenia.

Se ha consignado en la literatura científica que en esta patología se ven afectadas las funciones ejecutivas como la planificación, la memoria, la atención sostenida, entre otras (Ditman y Kuperberg, 2010). Junto con esto se ha caracterizado a la enfermedad por el deterioro cognitivo general en la etapa crónica en diversos dominios evaluados con test neuropsicológicos de inteligencia, de memoria, de atención, motores, de lenguaje y de funciones ejecutivas (Hotchkiss y Harvey, 1990; Heinrichs y Zakzanis, 1998; Gooding, Braun y Studer, 2006, y Ditman y Kuperberg, 2010). Los cambios neuroanatómicos que la enfermedad provoca en las fases tempranas, en especial las alteraciones corticales del lóbulo frontal, deterioran visiblemente las funciones antes señaladas. Con frecuencia, los sujetos afectados pueden presentar un mal ajuste a tareas sociales como la comunicación, incluso en la etapa prodrómica (McGorry et al, 2003). Por otra parte, la disminución del tamaño del hipocampo, los ventrículos agrandados ligeramente y otros cambios estructurales han sido pesquisados en personas con esquizofrenia de síntomas negativos. Esta evidencia neuroanatómica se ha vinculado con alteraciones cognitivas y comunicativas tempranas relevantes para el funcionamiento cognitivo general (Kandel, Schwartz y Jessell, 2001).

La gestión temática representa un complejo mecanismo discursivo desarrollado en diferentes niveles de procesamiento semántico y pragmático. El sistema cognitivo organiza e integra dichos procesos mentales a través de las funciones ejecutivas. Éstas dirigen tareas de automonitoreo para la resolución de problemas y la regulación de la conducta, según los parámetros pertinentes (Orellana, 2009). Según Stuss y Levine (2002), una de las tareas más relevantes de las funciones ejecutivas corresponde a la autorregulación estratégica del comportamiento con el propósito de alcanzar metas planificadas. Esta función con frecuencia se encuentra afectada en la esquizofrenia, ya que frente a situaciones no estructuradas, como es el caso de la interacción discursiva, el control inhibitorio de respuestas y elementos irrelevantes, se hace menos eficaz (Salavera y Puyuelo, 2010; Figueroa, 2015). Asimismo, el mantenimiento de la eficacia comunicativa depende, tanto de la planificación de la tarea discursiva, como de la atención sostenida para cumplir con la meta propuesta. La gestión temática en esquizofrenia es deficiente desde el primer 
episodio a causa de estos factores neurocognitivos, por lo que puede constituirse como indicador de déficit comunicativo primario.

A pesar de que entre los indicadores de la gestión temática se encuentran disfunciones que afectan diversas estructuras discursivas, resulta clave el hecho de que la limitación de la función intersubjetiva es la consecuencia de mayor gravedad, porque implica desvinculación social, estigma y el subsecuente deterioro en el funcionamiento psicosocial, como lo han señalado ampliamente diversos autores (Chaika y Lambe, 1985; Gernsbacher y Foertsch, 1999; Meilijson et al., 2004, y Kuperberg, 2010). Es importante señalar el carácter necesariamente limitado de este estudio, pero en la medida que se amplíe el corpus de pacientes de primer episodio de esquizofrenia y que se añadan nuevas pruebas y tareas comunicativas, será factible revelar con más claridad aspectos deficientes en los mismos indicadores que se investigaron, o bien, en otros que emerjan del trabajo. De la misma forma, se requiere realizar estudios en poblaciones con alto riesgo de desarrollar patología psiquiátrica para establecer perfiles lingüísticos específicos.

\section{CONCLUSIONES}

Es posible sintetizar los hallazgos del presente estudio como sigue:

1. Existen diferencias en la gestión temática entre los grupos de pacientes.

2. La variable estadio de la enfermedad reflejó entre las personas del grupo crónico una peor ejecución de los indicadores de gestión temática en general y para el primer episodio se observó un alto requerimiento de ayuda para el manejo de los objetivos comunicativos.

3. La variable sexo no reflejó estadísticamente una diferencia entre los participantes. Este hallazgo sugiere que sería necesario indagar desde diferentes enfoques esta variable para comprobar si se mantiene lo planteado por la literatura.

4. Los indicadores de gestión temática que ostentaron una mayor predictibilidad para el primer episodio son la mantención de la unidad temática, tópicos desarrollados e interacción entre vínculos referenciales. En los tres indicadores las personas con primer episodio de esquizofrenia presentaron dificultades y grandes requerimientos de apoyo, lo que implica que representan tareas comunicativas de alta demanda atencional que ya no pueden ser satisfechas por los recursos cognitivos de los afectados.

5. El indicador de gestión temática que mostró una mayor predictibilidad para cronicidad corresponde a la presencia de saltos topicales, rasgo que involucra un deterioro cognitivo de mayor envergadura.

6. El único indicador de gestión temática que se presentó entre los informantes 
del grupo control fue la presencia de saltos topicales. En la población sin patología psiquiátrica este fenómeno puede ser atribuido a fallas en las funciones ejecutivas o el proceso atencional propias de la población general.

En suma, dentro de la gama de alteraciones de diversas funciones del lenguaje en la esquizofrenia, el estudio de la gestión temática sobresale como un marcador precoz de alta sensibilidad por presentarse ya desde el primer episodio de esquizofrenia. Como posibles proyecciones del estudio, se debe tomar en cuenta el hecho de que no existen trabajos sobre el desempeño comunicativo en primer episodio y en población chilena, por lo que éste es, probablemente, un primer acercamiento. También parece necesario incorporar las variables sociodemográficas de los hablantes con patología con el fin de correlacionarlas con los fenómenos estudiados, pues se desconoce la realidad chilena a este respecto. Finalmente, es importante señalar que las alteraciones comunicativas, detectadas en el presente trabajo, pueden colaborar como una herramienta sensible para implementar diagnóstico clínico precoz de esquizofrenia, tarea crucial para evitar el deterioro cognitivo irreversible.

\section{REFERENCIAS}

Albentosa, J y Moya, A. (2001). Narración Infantil y Discurso: estudio lingüístico de cuentos en castellano e inglés. España: Ediciones de la Universidad de Castilla-La Mancha.

Andreasen, N.C. y W. Grove. (1995). Thought, language, and communication in schizophrenia: diagnosis and prognosis, Schizophrenia Bulletin 12, pp. 348359.

Belinchón M. (1988). Esquizofrenia y lenguaje: una aproximación psicolingüística. Estudios de Psicología, 33-34, 105-144.

Belinchón, M. (1991). Aspectos cognitivos en la esquizofrenia. Madrid: Trotta. Brown, G. y Yule, G. (1983). Análisis del discurso. Madrid: Visor.

Castilla del Pino, C. (1991). Aspectos cognitivos en la esquizofrenia. Trotta: Madrid. Chaika, E. y Lambe, R. (1985). The Locus of Dysfunction in Schizophrenic Speech. Schizophrenia Bulletin. Vol. 11, No 1.

Chapman, LJ y Chapman, JP. (1987). The search for symptoms predictive of schizophrenia. Schizophrenia Bulletin 13: 3, pp. 497-503.

Chapman, LJ; Chapman, JP; y Miller GA. (1964). "A theory of verbal behavior in schizophrenia”. In: Maher BA, editor. Progress in Experimental Personality Research. Vol. 1, pp. 49-77. New York: Academic Press.

Crow, T. (1997). Is schizophrenia the price homo sapiens pay for language? Schiz Res. 28:127-141.

De Lisi, LE. (2001). Speech disorder in schizophrenia: Review of the litera- 
ture and exploration of its relation to the uniquely human capacity for language. Schizophr Bull. 27(3): 481-496.

Ditman, T. y Kuperberg, G. (2010). Building coherence: A framework for exploring the breakdown of links across clause boundaries in schizophrenia. $J$. Neurolinguistics. May; 23 (3): 254-269.

DSM-IV. (1997). Manual Diagnóstico y Estadístico de los Trastornos Mentales. American Psychiatric Association (SCID-P; Primera et al, 1997a, b).

DSM-V. (2014). Manual Diagnóstico y Estadístico de los Trastornos Mentales. American Psychiatric Association.

Fernández, F. y Gil, L. (2000). Enlaces oracionales y organización retórica del discurso científico en inglés y español. España: Universitat de Valencia. Monographs v7 SELL.

Fernández, M. (2015). Lingüistica y déficit comunicativos. Madrid: Síntesis.

Figueroa, A. (2015). Análisis pragmalingüístico de los marcadores de coherencia en el discurso de sujetos con esquizofrenia crónica y de primer episodio. Tesis doctoral. España: Universidad de Valladolid.

Figueroa, A. (2017). Déficit primarios y secundarios en el lenguaje de personas con diagnóstico de esquizofrenia. Un ensayo de clasificación (en prensa).

Gallardo Paúls, B. y Moreno, V. (2005). Afasia no fluente. Materiales para su estudio. Vol. 2 Corpus PERLA. Valencia: Universidad de Valencia.

Gallardo Paúls, B. y Valles, B. (2008). Lingüística en contextos clínicos: la lingüística clínica. Lengua y Habla. Revista del Centro de Investigación y Atención Lingüistica C.I.A.L, pp. 32-50.

Gallardo Paúls, B. y Hernández Sacristán, C. (2013). Lingüistica Clínica. Un enfoque funcional sobre las alteraciones del lenguaje. Madrid: Arco.

Gernsbacher, MA. y Foertsch, J. (1999). "Three models of discourse comprehension”. In S. Garrod \& MJ Pickering (Eds.), Language processing. East Sussex, UK: Psychology Press. (pp. 283-299).

Givón, T. (1992) The grammar of referential coherence as mental processing instructions. Linguistics 30, pp. 5-55.

Gooding, DC.; Braun, JG., y Studer, JA. (2006). Attentional network task performance in patients with schizophrenia-spectrum disorders: Evidence of a specific déficit. Schizophrenia Research 88, pp. 169-178.

Gutiérrez Bravo, R. (2008). La identificación de los tópicos y los focos. Nueva Revista de Filología Hispánica. 51. pp. 363-401.

Gutiérrez Ordóñez, S. (2000). Temas, remas, focos, tópicos y comentarios. Cuadernos de Lengua Española. Madrid: Arco.

Halliday, M. A. K. (1994). Introduction to Functional Grammar, Londres: Edward Arnold ( $2^{\mathrm{a}}$ edición).

Heinrichs RW. y Zakzanis, KK. (1998) Neurocognitive deficit in schizophrenia: a quantitative review of the evidence. Neuropsychology 12: 426-445. 
Hockett, Ch. (1971). Curso de Lingüistica Moderna. Santiago: Editorial Universitaria.

Hotchkiss, A. P. y Harvey, P. D. (1990). Effect of distraction on communicative failures in Schizophrenic patients. American Journal of Psychiatry 147: 513-15. Hymes, D. (1996). "Acerca de la competencia comunicativa", Forma y Función (9), Santafé de Bogotá, junio, pp. 13-37.

Kandel, E.; Schwartz, J., y Jessell, T. (2001). Principios de neurociencia. Interamericana de España: McGraw-Hill.

Kay, SR.; Opler LA.; Spitzer, RL.; Williams, JB.; Fiszbein, A., y Gorelick, A. (1991). SCID-PANSS: two-tier diagnostic system for psychotic disorders. 1991. Compr. Psychiatry. Jul-Aug; 32(4): 355-61.

Keenan, E.O. y Schieffelin, B. (1976). "Topics as a discourse notion: A study of topic in the conversations of children and adults". In: Subject and topic. Edited by Li, Ch. New York: Academic Press.

Kuperberg, G. (2000). Schizophrenia and cognitive function. Current Opinion in Neurobiology, 10: 205-210.

Kuperberg, G. (2010). Language in Schizophrenia Part 1: An Introduction Language and Linguistics Compass, 576-589, Journal Compilation. USA: Blackwell Publishing.

Labov, W. y Fanshel, D. (1977). Therapeutic discourse: Psichotherapy as conversation. New York: Academic Press.

Laguna, E. y Turull, N. (2000). Aplicaciones del análisis del discurso en rehabilitación psicosocial con pacientes esquizofrénicos. Rev Psiquiatría, Fac. Med. Barna; 27(4): 193-200.

Leroy, F. y Beaune, D. (2008). Langage et schizophrénie: l'intention en question, Annales Médico Psychologiques 166 (8), pp. 612-619.

Levinson, S. (1983). Pragmatics. U.K: Cambridge University Press.

Manschreck, T. C.; Maher, B. A.; Milavetz, J. J.; Ames, D.; Weisstein, C. C., y Schneyer, M.L. (1988). Semantic priming in thought disordered schizophrenic patients. Schizophrenia Research 1, pp. 61-66.

McGorry, PD.; Yung, AR.; y Phillips, LJ. (2003). The <close-in> or ultra highrisk model: a safe and effective strategy for research and clinical intervention in prepsychotic mental disorder. Schizophr Bull 29(4): 771-790.

McKenna, P. J. y Oh, T. (2005). Schizophrenic speech: making sense of bathroots and ponds that fall in doorway. Londres: Cambridge University Press.

Meilijson, S. R.; Kasher, A., y Elizur, A. (2004). 'Language performance in chronic schizophrenia: a pragmatic approach'. Journal of Speech, Language, and Hearing Research 47(3): 695-713.

Morice, R. e Ingram, JCL. (1983). Language analysis in schizophrenia: Diagnostic implications. Australian and New Zealand. J Psychiatry; 16: 11-21.

Orellana, G. (2009). Conductas disejecutivas en primer episodio de esquizofrenia: 
rol de la atención ejecutiva y de la autorregulación estratégica. Tesis doctoral en Ciencias Biomédicas. Santiago de Chile: Universidad de Chile.

Piro, S. (1987). El lenguaje esquizofrénico. México: Fondo de Cultura Económica. Premack, D., \& Woodruff, G. (1978). Cognition and Consciousness in Nonhuman Species - Reply. Behavioral and Brain Sciences, 1(4), 616-628.

Salavera, C. y Puyuelo, M. (2010). Aspectos semánticos y pragmáticos en personas con esquizofrenia. Revista de Logopedia, Foniatría y Audiología. Vol 30, April-June, pp. 84-93.

San Martín, A. y Guerrero, G. (2015). Estudio Sociolingüístico del Español de Chile (ESECH): recogida y estratificación del corpus de Santiago. Boletín de Filología, Tomo L Número 1: 221-247.

Sánchez, R.; Téllez, G.; y Jaramillo, L. (2012). Edad de inicio de los síntomas y sexo en pacientes con trastorno del espectro esquizofrénico. Biomédica, [S.I.], v. 32, n. 2, pp. 206-213.

Soto, G.; Hasler, F., y García, R. (2011). "Lenguaje, cognición e interacción. El dominio de la gestión de expectativas". En Figueroa, A. y Durán E. (coords) Psicolingüística Clinica aplicada a las enfermedades mentales. Lingua \& Psyché. Corporación Chilena para la esquizofrenia. Año: pp. 151-170. Santiago: CORES.

Spitzer, M.; Weisker, I.; Winter, M.; Maier, S.; Hermle, L. y Maher, B.A. (1994). Semantic and phonological priming in schizophrenia, Journal of Abnormal Psychology 103, pp. 485-494.

Stuss, DT. y Levine, B. (2002). Adult clinical neuropsychology: lessons from studies of the frontal lobes. Annu Rev Psychol. 53; 401-3.

Tirapu-Ustárroz, J.; Pérez-Sayes, G.; Erekatxo-Bilbao, M., y Pelegrín-Valero, C. (2007). ¿Qué es la teoría de la mente? REV NEUROL 2007; 44 (8): 479-489.

Tomlin, R.S.; Forrest, L.; Pu, M.M., y Kim, M. H. (1997). "Discourse Semantics". En T.A. Van Dijk (Ed.), Discourse as Structure and Process. Discourse Studies: A Multidisciplinary Introduction: Vol I (pp. 63-111). Londres: Sage. (Trad cast. El discurso como estructura y proceso. Estudios sobre el Discurso I: Una introducción multidisciplinaria. Barcelona: Gedisa).

Usall, J. (2003). Diferencias de género en la esquizofrenia. Rev. Psiquiatría Fac. Med. Barna 2003; 30 (5): 276-287.

Van Dijk, T. (1980). Estructuras y funciones del discurso. México: Siglo XXI.

Van Dijk, T. (1995). "Discourse semantics and ideology". Discourse and society 6.2: 243-289.

Vargas, M. (2003). Posibilidades de rehabilitación neurocognitiva en la esquizofrenia. II Congreso Internacional de Neuropsicología en Internet, Revista de Neurología 38 (5), pp. 473-482. 